\title{
Editorial:
}

\section{Does the Training in Geriatrics Affect a Doctor's Decision to Care for the Elderly?}

Three facts are already well-known: the aging of the Canadian population and the impact it is having on the health care system at the administrative, financial, and ethical levels; the shortage of doctors interested in practising geriatric medicine; the lack of training for doctors in geriatrics.

Indeed, Quebec has not been very successful in recruiting physicians who wish to practise geriatric medicine in homes for the aged or within the framework of home care community programs. As a specialty in medicine, geriatrics remains unappealing to future doctors (Duthie et al., 1987). As Somers observed, the teaching of geriatrics has long qualified as one of the four 'orphans' within medicine, along with preventive medicine, health management, and medical ethics (Somers, 1987). This is reflected in the difficulty which doctors experience in detecting and diagnosing certain problems affecting the aging population within their practice (loss of autonomy, dementia, incontinence, or depression) (Siu et al., 1988; Beaulieu and Leclère, 1991), or in investigating (Radecki et al., 1988) and treating certain ailments (Larson et al., 1991; Greenfield et al., 1987).

In an article published in this issue, Judith Globerman discusses the factors which have a bearing on a doctor's decision to commit him/herself to delivering health care to the elderly. She focusses on the doctor's personality and style of practice, his/her personal contacts with the elderly, as well as his/her educational experiences.

Many questions arise. Do the attitudes and the knowledge pertaining to the aged influence the future doctor's decision to deliver care to the elderly? Can the knowledge and the attitudes of medical students be altered through the training programs in geriatrics? Which factors determine the success of the training programs?

A survey of publications written by Coccaro, Adelman and Beissner is particularly revealing (Coccaro and Miles, 1984; Adelman and Albert, 1987; Beissner, 1990). The conclusions are sometimes contradictory, or they serve to show that education has in fact very little impact on the student's attitudes and on his/her desire to enter into geriatric medicine. These results were strongly influenced by the methodology and measuring tools utilized. The tools most commonly used to evaluate the level of knowledge and the attitudes towards the elderly were somewhat inadequate: the concepts measured varied from one instrument to another, thereby making it difficult to draw any kind of comparison; the content measured was sometimes dated; the instruments utilized were not particularly sensitive to changes; 
important variables influencing the physician's desire to care for the elderly were not incorporated; few studies included control groups; attitude changes were measured on a short-term basis, rarely on a long-term basis. Thus, very few studies confirmed whether the student's desire to care for the aged in fact materialized later on.

Nevertheless, some important trends do emerge from these studies. For instance, medical students can enhance their knowledge in geriatric medicine by going through a well-planned teaching program. Moreover, there seems to be a positive link between the acquisition of such knowledge and the development of favourable attitudes towards the elderly (Linn and Zeppa, 1987).

In general, students in their first year of medicine have relatively positive attitudes towards the aged. However, over time, these students are confronted with a good deal of stress caused by their medical studies, the administrative problems within the field of medicine, the affective areas frequently troubled by the reality of chronic diseases and suffering. The development of a teaching program in geriatrics which would value a global and humanistic approach might slow down this phenomenon, at least on short-term basis.

Certain factors have a more significant impact on the physician's attitudes towards the elderly and on his/her desire to practice geriatric medicine. Previous experiences with the elderly are very important, especially when they have been of a positive nature (Beissner, 1990; Green et al., 1983; Adelman and Albert, 1987; Linn and Zeppa, 1987). Such experiences could be personal in nature such as a contact with a grandparent, a summer job in a home for the aged, or meetings with elderly patients during the clinical course of training. Teachers generally agree on the importance of concentrating on the quality of the meetings instead of focussing on their numbers, as long as the student is working within a good cognitive and affective framework.

Students must be invited to meet with the elderly as soon as they enter into medicine; these meetings could even be incorporated into earlier intergenerational programs offered within the context of a primary, secondary or collegial curriculum. In addition, medical students must interact with a wide variety of elderly persons, all with differing levels of autonomy, in order to fully grasp the heterogeneousness of the elderly population, thus breaking down the widespread stereotype present in hospitals which contends that an older person is a severely handicapped one. A variety of work settings must be identified: the aged's home, the community centre, the day care centre, home care programs, homes for the aged, as well as hospitals. This kind of exposure must continue throughout the years of training.

The students' personality is also an important variable. Students who are more open to a global and humanistic approach in medicine would presumably be more likely to care for the elderly. This type of personality profile can only be detected through the selection process which takes place in medicine. Therefore, selection must not only be based on academic achieve- 
ment, but also on personality, on values and on attitudes. The University of Montreal, has been following this kind of procedure for several years now.

The personal sense of achievement which results from delivering care to the elderly is also a determinant factor (Green et al., 1983). This feeling grows in the presence of doctors whose role model is as stimulating on an intellectual level as it is on a human level. Presently, the dearth of geriatricians and family physicians interested in the field of geriatrics forces these doctors into devoting most of their working hours to their patients' needs, much to the detriment of the academic, research and publication components of their work (Siu et al., 1989; Vivell et al., 1987). This interferes with the advancement of the discipline and it does not allow for the emergence of prestigious role models such as the ones present in the other longestablished specialties.

In addition, the working environment chosen by these teaching physicians must be supportive and encouraging. The teaching environments most conducive to the practice of geriatrics are often the ones most receptive to an interdisciplinary approach, not only within the various medical disciplines but also with other gerontological disciplines, to humanism, and to a community approach. The University of Nottingham has created a model which illustrates this approach very well (Wattis et al., 1986).

Other factors influencing doctors in their choice of practice which do not directly result from education include the complexity of a geriatrics practice from an administrative and a clinical point of view and the remuneration which does not always reflect the hours that each physician devotes to his/her geriatric practice (Barker and Williamson, 1986).

Many studies, both in the United States and in Canada, have demonstrated that training programs in geriatrics have not been introduced everywhere and that many are not yet mandatory (Reuben et al., 1990; Vivell et al., 1987; Canadian Medical Association, 1987). However, as Besdine pointed out, the field of geriatrics has grown very rapidly over the past ten years and it is on the way to becoming a mature discipline (Besdine, 1989). As far as the medical establishment in Quebec is concerned, considerable efforts have been made in the last ten years to develop a geriatric teaching program which could be incorporated at the pre-graduate as well as the post-graduate levels. A variety of teaching methods have been adopted.

Obviously, a good deal of patience will be needed, for these various endeavours will not produce immediate results. However, the pressure generated by demography, combined with medical demography may prove to be a more powerful force than education itself in motivating the doctors to choose the field of geriatrics. The training the physicians receive will always be reflected in the quality of the practice they offer their elderly patients. This kind of training cannot come about without the express contribution of a nucleus of teachers which in turn is fully supported by universities who value geriatrics. 


\section{References}

Adelman, R.D., \& Albert, R.C. (1987). Medical Student Attitudes Toward the Elderly: A Critical Review of the Literature. Gerontology and Geriatrics Education, 7, 141-155.

Barker, W., \& Williamson, J. (1986). Survey of Recently Appointed Consultants in Geriatric Medicine. British Medical Journal, 293, 896-898.

Beaulieu, M.-D., \& Leclère, H. (1991). Nature des difficultés de la pratique médicale: les omnipraticiens s'expriment. Bulletin. Corporation professionnelle des médecins du Québec, 31, 17-22.

Beissner, K. (1990). Health Professional Students' Intentions Toward Geriatric Specialization: A Review of Contributing Factors. Gerontology and Geriatrics Education, 10, 71-89.

Besdine, R.W. (1989). The Maturing of Geriatrics. New England Journal of Medicine, 320, 181-182.

Canadian Medical Association. (1987). Les soins de santé pour gens âgés. Deuxième partie. Canadian Medical Association Journal, 137, 544c-544d.

Coccaro, E.F., \& Miles, A.M. (1984). The Attitudinal Impact of Training in Gerontology/Geriatrics in Medical School: A Review of the Literature and Perspective. Journal of the American Geriatrics Society, 32, 762-768.

Duthie, E.H., Donnelly, M.B., \& Kirsling, R.A. (1987). Fourth-Year Students' Preference for Geriatrics as a Career. Journal of Medical Education, 62, 511-514.

Green, S.K., Keith, K.J., \& Pawlson, L.G. (1983). Medical Students' Attitudes Toward the Elderly. Journal of the American Geriatrics Society, 31, 305-309.

Greenfield, S., Blanco, D.M., \& Elashoff, R.M. (1987). Patterns of Care Related to Age of Breast Cancer Patients. Journal of the American Medical Association, 257, 2766-2770.

Larson, D.B., Lyons, J.S., \& Hohmann, A.A. (1991). Psychotropics Prescribed to the US Elderly in the Early and Mid 1980s: Prescribing Patterns of Primary Care Practitioners, Psychiatrists, and Other Physicians. International Journal of Geriatric Psychiatry, 6, 63-70.

Linn, B.S., \& Zeppa, R. (1987). Predicting Third Year Medical Students' Attitudes Toward the Elderly and Treating the Old. Gerontology and Geriatrics Education, 7, 167-175.

Radecki, S.E., Kane, R.L., \& Solomon, D.H. (1988). Are Physicians Sensitive to the Special Problems of Older Patients? Journal of the American Geriatrics Society, 36, 719-725.

Reuben, D.B., Fink, A., \& Vivell, S. (1990). Geriatrics in Residency Programs. Academic Medicine, 65, 382-387.

Siu, A.L., Ke, G.Y., \& Beck, J.B. (1989). Geriatric Medicine in the United States. The Current Activities of Former Trainees. Journal of the American Geriatrics Society, 37, 272-276.

Siu, A.L., Leake, B., \& Brook, R.H. (1988). The Quality of Care Received by Older Patients In 15 University-Based Ambulatory Practices. Journal of Medical Education, 63, 155-161.

Somers, A.R. (1987). Four "Orphan" Areas in Current Medical Education: What Hope for Adoption? Family Medicine, 19, 137-140.

Vivell, S., Solomon, D.H., \& Beck, J.C. (1987). Medical Education Responds to the 20th Century's Success Story. Journal of the American Geriatrics Society, 35, 1107-1115. 
Wattis, J.P., Smith, C.W., \& Binns, V. (1986). Medical Students' Attitudes to Old People and Career Preference: a Comparison of Two Universities. Medical Education, 20, 498-501.

Paule Lebel 